\title{
The effects of pre-shock and handling on the startle response in the rat'
}

\author{
JAMES H. KORN AND K. E. MOYER ${ }^{2}$ \\ CARNEGIE INSTITUTE OF TECHNOLOGY
}

\begin{abstract}
Five days of shock ( 5 shocks of $4.5 \mathrm{ma}, 0.2 \mathrm{sec}$. duration at 1 sec. intervals) produced an enhanced startle response if Ss were startled shortly after the last shock experience. However, if the Ss were startled $24 \mathrm{hr}$. after the last shock experience, the response was depressed. Control group results indicate that this depression was due to the Ss having become habituated to the presentation of novel stimulation.
\end{abstract}

\section{Problem}

Bartoshuk (1959) has shown that the size of the startle response is directly related to Ss level of arousal when the startle stimulus is presented. Moyer (1963), attempting to explain a high initial startle in a series of startle experiences, hypothesized that the novelty of the initial experience raised the arousal of the $S$ and resulted in increased startle magnitude. This hypothesis lead to the prediction that pre-exposure to the startle situation (without the startle stimulus) would lead to decreased startle magnitude when the startle stimulus was finally presented. This prediction was supported (Moyer \& Korn, 1965)。

The question now asked is whether exposure to novel situations other than the startle situation itself will result in a reduction in Ss arousal level when it is placed in the startle situation, and will this arousal reduction be reflected in a smaller startle response. This study also investigated the effect of exposing $\mathrm{S}$ to a noxious novel environment by presenting shock during the exposure period. Finally, since the shock and the handling involved in introducing $S$ into the novel situation may in itself be arousing, the effects of these experiences on the startle response were investigated immediately after exposure, or $24 \mathrm{hr}$. after exposure. Brown, Meryman, \& Marzocco (1956) failed to observe any effect of shock administered in the startle situation on the startle response itself, but suggested that the response might have been facilitated if the shock had been given in a situation which differed from that in which startle was measured.

\section{Method}

The apparatus is described in detail elsewhere (Moyer, 1963). It consisted of a Plexiglas confining box, 2-3/4 $\times 6 \times 4$ in, with a grid floor mounted on a postage-scale sensing unit which was connected to a paper recorder system. A $6 \mathrm{~mm}$ blank starting pistol held 48 in from $\mathrm{S}$ produced the startle stimulus. Shock was administered by a Model 228 Applegate stimulator in a $12 \times 10 \times 8$ in grill box which had a floor of $1 / 8$ in brass rods.
The Ss were 102 male albino rats from the Carnegie Tech colony which were randomly assigned to one of three groups of 34 Ss each: a Shocked group was given five shocks ( $4.5 \mathrm{ma}, 0.2 \mathrm{sec}$. duration, at $1 \mathrm{sec}$. intervals) per day for five successive days; a Handled group was placed in the grill box for $6 \mathrm{sec}$./day for five days, but was not shocked; an Unhandled group remained undisturbed in their home cages during the five days that the other groups were being treated. Half of the Ss in the Shocked and Handled groups were startled immediately after their last treatment, while the other half were tested $24 \mathrm{hr}$. later. For the Unhandled group, 1/2 the Ss were tested with the Immediate groups and 1/2 with the $24 \mathrm{hr}$. groups.

The startle test consisted of placing the $S$ in the confining box and permitting one minute of adaptation time. An initial shot was then fired which caused $S$ to stop its exploratory movements. This was followed by five additional shots at $30 \mathrm{sec}$. intervals.

\section{Results}

The mean startle responses over the five trials of the immediate test were: Shocked group, 22.6; Handled group, 16.8; Unhandled group, 16.2. The means on the $24 \mathrm{hr}$. test were: Shocked, 10.5; Handled, 9.1; Unhandled, 16.5. Analysis of variance showed significant effects of Test (Immediate vs. $24 \mathrm{hr}$; $\mathrm{F}=8.36, \mathrm{df}=1 / 96, \mathrm{p}<.01$ ) and of the Treatments $x$ Test interaction $(F=2.58$, $\mathrm{df}=2 / 96, \mathrm{p}<.10)$. This interaction can be attributed largely to the high startle mean for the Shocked group relative to the control groups on the immediate test and to the low means for the Shocked and Handled groups relative to the Undisturbed group on the $24 \mathrm{hr}$. test.

\section{Diseussion}

This experiment further clarifies the relationships between novelty, arousal, and startle. Both the shocked and the handled groups that were startled $24 \mathrm{hr}$. after their experimental manipulation showed a depression of the startle response compared with unhandled controls. This seems to indicate that prior exposure to any novel situation leads to a reduction in the arousing properties of new stimulus situations and results in a reduction in startle magnitude. Even the association of the noxious shock stimulus with the novel experience did not alter the effect of that experience in reducing the novelty associated with the startle situation.

The results of testing the Ss immediately after their exposure to the novel situation further supports the hypothesis that increased arousal facilitates startle. The Ss exposed to five shocks of 4.5 ma were clearly 
aroused by the shock experience and they gave increased startle responses. Thus, the speculation of Brown etal. (1956) appears to be correct; shock does facilitate startle when given outside the startle situation if the $S$ is tested shortly after the shock.

It may be that the procedure of placing the Ss in the grill box without shock before startle had a similar arousing effect since there was little difference in the means for the Handled and Unhandled groups on the Immediate test, while the mean startle for the Handled group was lower on the $24 \mathrm{hr}$. test.

\section{References}

Bartoshuk, A. K. Electromyographic reactions to strong auditory stimulation as a function of alpha amplitude. J. comp. physiol. Psychol., 1959, 52, 540-545.
Brown, J. S., Meryman, J. W., \& Marzocco, F. N. Sound-induced startle response as a function of time since shock. J. comp. physiol. Psychol., 1956, 49, 190-194.

Moyer, K. E. Startle response: Habituation over trials and days, and sex and strain differences, J. comp. physiol. Psychol., $1963,56,863-865$.

Moyer, K. E., \& Korn, J. H. Habituation of the startle response and of heart rate in the rat. Paper read at Midwestern Psychological Association, Chicago, May, 1965.

\section{Noter}

1. This investigation was supported in part by Research Grant M-1298 from the National Institute of Health, United States Public Health Service.

2. The authors wish to express appreciation to Paul Mottey who served as a research technician on this project. 